Nov 2017 a Abr $2018-v .8-n .1$

\title{
Caracterização geotécnica visando a implantação de trincheira drenante no município de Palmas/TO.
}

O presente trabalho tem por objetivo caracterizar o solo de uma área susceptível a alagamento no município de Palmas/TO e analisar se o mesmo suporta as limitações para implantação da trincheira drenante como sistema drenante alternativo de baixo custo. Os resultados dos ensaios geotécnicos do solo e a análise granulométrica demostraram que o solo é areno siltoso com pequena quantidade de pedregulho, e $55 \%$ de finos, a classificação conforme o Soil Conservation Service o solo se enquadra como solos arenosos com baixo teor de argila total, a massa especifica grão foi de $2,65 \mathrm{~g} / \mathrm{cm} 3$, devido à presença do mineral quartzo e caulinita. O índice de plasticidade foi de $17,2 \%$ valor que estabelece a plasticidade do solo como altamente plástica. Conforme a Carta de Plasticidade de Casagrande, a amostra de solo pode ser classificada como solos argilosos de baixa compressibilidade. Os ensaios de dispersão rápida com submersão em solução de $0.001 \mathrm{~N}$ de hidróxido de sódio, o solo é classificado como sendo não dispersivo. O ensaio de desagregação do solo a reação da amostra à inundação foi a de faturamento. Os valores de condutividade hidráulica vertical encontrados para o anel metálico, foi de 49,284 $\mathrm{mm} / \mathrm{h}$, determinando que o solo e correlacionável a franco arenoso. Conclui-se que solo tem a capacidade de suporte da trincheira possuindo condutibilidade hidráulica e possui caráter não dispersivo, enquanto que o de desagregação indica um índice de colapsibilidade baixo.

Palavras-chave: Alagamento; Trincheira drenante; Sistema alternativo.

\section{Geotechnical characterization objetiving the implantation of trencheira drainage in the municipality of Palmas/TO.}

\begin{abstract}
This study aims to characterize the soil of an area susceptible to flooding in the city of Palmas/TO and consider whether it supports the limitations for implementation of the drainage trench as draining low cost alternative system. The results of geotechnical studies of the soil, the granulometric analysis demonstrated that the soil is sandy silt with a small amount of gravel, and $55 \%$ fines, the classification according to the Soil Conservation Service soil is characterized as sandy soils with low content of total clay the grain bulk density was $2.65 \mathrm{~g} \mathrm{/} \mathrm{cm3} \mathrm{due} \mathrm{to} \mathrm{the} \mathrm{presence} \mathrm{of} \mathrm{the} \mathrm{mineral} \mathrm{kaolinite} \mathrm{and} \mathrm{quartz.} \mathrm{The} \mathrm{plasticity} \mathrm{index}$ value was $17.2 \%$ establishing the plasticity of the soil as highly plastic. As chart Plasticity Casagrande, the soil sample can be classified as clayey soils of low compressibility. Rapid dispersion testing with submergence in $0.001 \mathrm{~N}$ sodium hydroxide, the soil is classified as non-dispersive. The soil disaggregation test the reaction of the sample to the flooding was the billing. The hydraulic conductivity values found for the metal ring was $49.284 \mathrm{~mm} / \mathrm{h}$, determining the soil and correlated with the sandy loam. It is concluded that soil has the trench carrying capacity having hydraulic conductivity and soil has not dispersive character while the breakdown indicates a low collapsibility index.
\end{abstract}

Keywords: Flooding; Trench drainage; Alternative system

Topic: Engenharia Ambiental

Reviewed anonymously in the process of blind peer
Received: $\mathbf{1 1 / 0 1 / 2 0 1 8}$

Approved: 22/04/2018
Amitai Silva Lima Junior

Universidade Federal do Tocantins, Brasil http://lattes.cnpq.br/5065965469024627 amitaijunior@gmail.com

Rose Mary Gondim Mendonça Universidade Federal do Tocantins, Brasil http://lattes.cnpq.br/5030489205608727 rosemarl@mail.uft.edu.br

Paula Raquel Barreto Rodrigues

Universidade Federal do Tocantins, Brasil http://lattes.cnpq.br/5080061539701821 barretopaularaquel@gmail.com

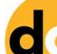

DOI: 10.6008/CBPC2237-9290.2018.001.0004
Domingos Bonfim Ribeiro dos Santos Universidade Federal do Tocantins, Brasil http://lattes.cnpq.br/5659839359957827 migos8@hotmail.com

Thaynan Gomes Andrade

Universidade Federal do Tocantins, Brasil http://lattes.cnpq.br/6699659363036388 thaynan47@hotmail.com

Referencing this:

LIMA JUNIOR, A. S.; MENDONÇA, R. M. G.; RODRIGUES, P. R. B. SANTOS, D. B. R.; ANDRADE, T. G.. Caracterização geotécnica visando a implantação de trincheira drenante no município de Palmas/TO. Natural Resources, v.8, n.1, p.31-40, 2018. DOI: http://doi.org/10.6008/CBPC2237-9290.2018.001.0004 


\section{INTRODUÇÃO}

A compactação e impermeabilização do solo são uns dos principais impactos causados pela urbanização que tende de dificultar e impossibilitar a infiltração da água no solo, interferindo a continuidade do ciclo hidrológico de uma bacia. Segundo Silva (2007) e Tucci (2000), devido ao crescimento urbano não planejado, algumas bacias apresentam altos índices de impermeabilização, o que tem provocado aumento nos volumes de escoamento superficial, enchentes, erosões e assoreamento da macrodrenagem.

Entende-se que o manejo das águas pluviais urbanas corresponde ao conjunto de práticas de infraestrutura que visam o amortecimento de vazões de cheias para tratamento e disposição final das águas pluviais drenadas, em conjunto com outras ações de planejamento e de gestão da ocupação do espaço territorial urbano (BRASIL, 2007). Nesse contexto a drenagem urbana tem sido um dos grandes desafios das cidades. A falta de infraestrutura, o crescimento desordenado entre outros fatores tem causado grandes transtornos à população e seus reflexos são vistos anualmente nos períodos de chuvas.

A adoção do sistema de drenagem tradicional, que busca evacuar rapidamente as águas pluviais para a jusante, resulta em um aumento nos volumes escoados. As vazões de pico e uma redução no tempo de escoamento fazem com que os hidrogramas de cheias sejam mais críticos, aumentando-se, assim, a frequência e a gravidade das inundações. Assim faz-se necessário minimizar os impactos causados pelo acúmulo de água superficial, por isso, pesquisadores tem desenvolvido sistemas de drenagem alternativos.

Estes sistemas servem como condicionantes do escoamento superficial e auxiliam a infiltração de água no solo. Segundo Carvalho (2013), o uso desses sistemas promove a descentralização dos fluxos superficiais, e a recarga do lençol freático. As soluções de infiltração são geralmente escolhidas por razões hidráulicas, tendo função de redução das vazões de pico e do volume escoado (BARRAUD et al.,1998).

De acordo com Brito (2006) e Souza (2002), esses sistemas alternativos apresentam diversas vantagens em relação à solução tradicional não só em termos quantitativos pela redução das vazões a jusante, mas também em termos qualitativos, desempenhando um importante papel na remoção e no controle de poluentes do escoamento superficial e colaborando com a melhoria da qualidade das águas no meio urbano.

Segundo Baptista et al. (2005) esses sistemas alternativos são classificados em três tipos distintos, conforme sua posição de implantação, que podem ser: técnicas de controle na fonte, técnicas lineares e técnicas de controle centralizado. O sistema de trincheira de drenante é uma técnica linear, que armazena a água precipitada por tempo suficiente para sua infiltração no solo. Funciona como reservatório convencional de amortecimento de cheias, uma vez que favorece a infiltração da água no solo, reduzindo as vazões máximas de enchente (AZZOUT et al.,1994).

A trincheira drenante tem, portanto, a função de abater descargas de pico de um escoamento superficial e promover a recarga do aquífero, no entanto, outra importante função é a de promover o melhoramento da qualidade das águas pluviais pela infiltração no solo, conforme Silva (2007). Dessa forma, o presente trabalho tem por objetivo realizar a caracterização geotécnica do solo e analisar se o mesmo 
suporta as limitações para implantação da trincheira drenante como sistema drenante alternativo de baixo custo.

\section{METODOLOGIA}

\section{Coleta e preparação das amostras de solo}

Para a realização dos ensaios foi coletada uma amostra de solo no município de Palmas/TO, ponto 22 L 789656,68 Sul UTM 8872995,02 Leste, próximo à Avenida JK, saída para Paraíso do Tocantins. A coleta ocorreu na micro bacia do Córrego Brejo Comprido, no compartimento geomorfológico da Depressão do Tocantins em solos oriundos da pedogênese de sedimentos intemperizados de formação sedimentar arenosa, correlacionável a Formação Pimenteiras, sendo o solo correspondente ao Latossolo vermelhoamarelo distrófico descrito por Santos (2000). A escolha da área para a instalação da trincheira de infiltração obedece alguns critérios estabelecidos por Hasegawa et al. (1999), citado por Souza (2002), para que o dispositivo não comprometa a preservação do solo.

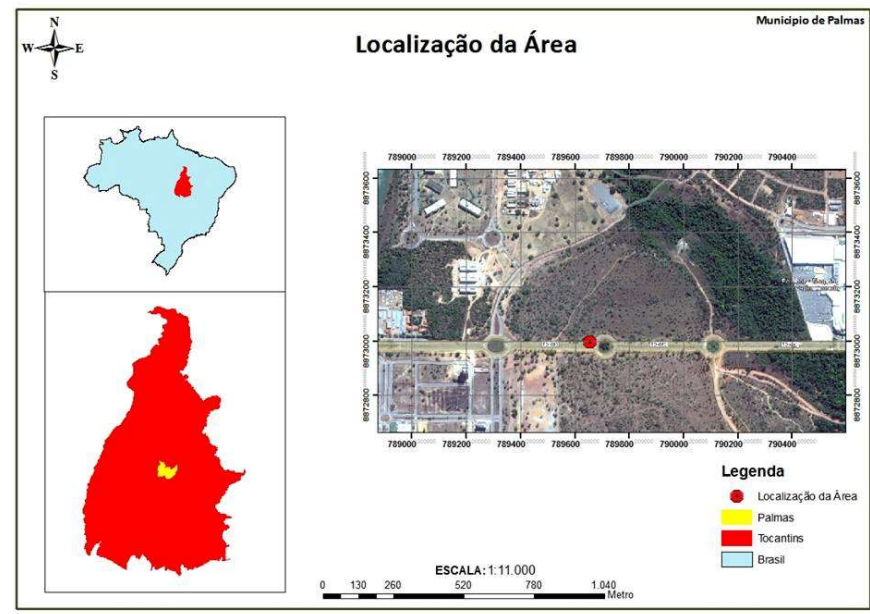

Figura 1: Mapa de localização da área de estudo.

A coleta foi realizada a uma distância de 1 metro da margem do asfalto, foi nivelado o local de coleta junto à camada asfáltica, e em seguida retirou-se uma amostra de $15 \mathrm{~kg}$ de solo a uma profundidade de $1 \mathrm{~m}$ no perfil onde se instalaria a zona de infiltração da trincheira. A amostra coletada foi encaminhada ao Laboratório de Geologia e Geomorfologia da Universidade Federal do Tocantins. Após a chegada, foi seca ao ar livre e posteriormente desagregado e destorroado. Em seguida a amostra foi quarteada, e parte da mesma foi passada na peneira $2 \mathrm{~mm}$ (\#10), para a realização do peneiramento grosso, sedimentação, peneiramento fino 0,074 mm (\#200) e massa especifica dos grãos. E uma alíquota do passante na peneira de $2 \mathrm{~mm}$ foi passada na de 0,42 mm (\#40) para a realização dos ensaios de índice de consistência (Limite de Liquidez, Limite de Plasticidade e Índice de Plasticidade).

\section{Caracterização Geotécnica}

A caracterização física do solo foi feita com a finalidade de determinar os parâmetros e prever o comportamento do mesmo dentro do sistema de trincheira drenante. Os ensaios realizados foram: 


\section{Granulometria}

A análise granulometria foi realizada conforme estabelecido na norma ABNT NBR 7181/84 que consiste, em duas fases: peneiramento e sedimentação. O peneiramento consiste em determinar o peso seco da amostra, sendo esse o peso do material que passa em cada peneira assim considerado como a 'porcentagem passante', sendo representado graficamente em função da largura da malha da peneira, está em escala logarítmica. A abertura nominal da peneira é considerada como o 'diâmetro' das partículas, tratando-se evidentemente de um 'diâmetro equivalente', pois as partículas não são esféricas (PINTO, 2000). A classificação granulométrica das partículas foi feita segundo seus diâmetros equivalentes, conforme a escala granulométrica da ABNT NBR 6502/95.

\section{Massa Especifica do Grão}

O método utilizado para determinação da massa específica dos grãos foi o do picnômetro com água, conforme a norma DNER-ME 093/94, para determinação da massa específica dos grãos.

\section{Massa Específica Aparente do Solo}

Para a determinação da massa especifica aparente ou densidade global do solo foram coletadas três amostras indeformadas de solo obtidas a partir da cravação de três cilindros com volume pré-estabelecido e com auxílio de uma marreta e uma régua de madeira que distribui a carga. Após a penetração de cada anel no solo foi realizada uma escavação envolta do mesmo para sua retirada, em seguida foi envolvido em filme plástico para impedir a perda de umidade e de material durante no transporte. Em laboratório, as amostras de solo de cada anel foram pesadas e levadas à estufa a temperatura de $105^{\circ} \mathrm{C}$ por um período de 24 horas, e posteriormente foram pesadas novamente. A massa específica aparente seca de cada amostra é o quociente entre a massa seca verificada e o volume de cada cilindro.

\section{Limite de Plasticidade}

O limite de plasticidade (LP) foi determinado pelo cálculo da porcentagem de umidade para qual o solo começa a se fraturar quando se tenta moldá-lo, conforme ABNT NBR 7180/88.

\section{Limite de Liquidez}

O ensaio de limite de liquidez foi realizado conforme a norma ABNT NBR 6459/84, para determinar o teor em água acima do qual o solo adquire o comportamento de um líquido.

\section{Índice de Consistência}

O índice de plasticidade foi obtido pela diferença entre os limites de liquidez (LL) e o de plasticidade (LP):

$$
I P=L L-L P
$$


A Tabela 1, apresenta a classificação dos solos quanto ao índice de plasticidade conforme proposição de Jenkins.

Tabela 1: Classificação do índice de plasticidade do solo.

\begin{tabular}{ll}
\hline Tipos de Solos & Índice de Plasticidade (IP) \\
\hline Fracamente plástico & $1<\mathrm{IP}<7$ \\
\hline Medianamente plástico & $7<\mathrm{IP}<15$ \\
\hline Altamente plástico & $\mathrm{IP}>15$ \\
\hline
\end{tabular}

\section{Umidade do Solo}

A umidade de um solo foi determinada a partir da razão entre o peso da água contida num certo volume de solo e o peso da parte sólida existente neste mesmo volume. Para a obtenção da umidade procedeu-se a pesagem de uma amostra de solo úmido $(\mathrm{Ph})$, sendo que o mesmo foi levado a estufa à 110 ${ }^{\circ} \mathrm{C}$, por aproximadamente 24 horas, até o peso constante que foi considerado o peso seco (Ps). A diferença entre eles (Ph - Ps) é o peso da água (Pa) (ABNT, 6457/86).

\section{Ensaios de Dispersão Rápida}

Foi colocado uma amostra indeformada de solo (torrão cúbico de $6 \mathrm{~cm}$ de aresta), sobre uma superfície permeável e em seguida ocorreu a submersão em uma solução de 0,001 N de NaOH (hidróxido de sódio). Após a submersão da amostra, a mesma foi deixada em repouso durante 1 hora. Depois desse período de espera ocorreu a classificação do solo quanto à dispersão através de análise visual de acordo com os critérios descritos a seguir: Não Dispersiva: $O$ torrão pode espalhar-se no fundo do recipiente, porém não se observa sinal de turvação causada por colóides em suspensão; Levemente Dispersiva: Aparecimento de turvação à superfície do torrão; Moderadamente Dispersiva: Aparecimento de nuvem de colóides em suspensão facilmente reconhecível, frequentemente espalhando-se em finas estrias na base do recipiente, e não chegando a cobrir toda a sua área; e Altamente Dispersiva: Nuvem coloidal cobrindo toda a base do recipiente frequentemente em uma camada muito fina. Em casos extremos a água torna-se turva.

\section{Desagregação do Solo, Infiltração}

O ensaio de desagregação foi realizado com submersão controlada em estágios. No primeiro estágio, a amostra indeformada de solo (torrão cúbico de $6 \mathrm{~cm}$ de aresta), foi colocada sobre uma superfície permeável, onde permaneceu cerca de trinta minutos com água na altura da base. No segundo estágio o nível foi elevado para $1 / 3$ da altura da amostra, onde permaneceu por 15 minutos. No terceiro estágio elevou-se o nível para $2 / 3$ da altura da amostra, permanecendo, também, por 15 minutos. No último estágio ocorreu a submersão total da amostra, permanecendo até 24 horas contados a partir do início do ensaio.

Durante as submersões foram observados e anotados os períodos e a forma em que ocorreu às alterações no cubo de amostra. Após o término do ensaio, além de se verificar a desagregrabilidade do solo, 
foi realizada a classificação quanto a reação à inundação de acordo com os seguintes fenômenos: Sem Resposta: quando a amostra mantém sua forma e tamanho originais; Abatimento: quando a amostra se desintegra formando uma pilha de material desestruturado; Fraturamento: quando a amostra se quebra em fragmentos mantendo a forma original das faces externas; e Dispersão: quando as paredes da amostra se tornam difusas com o surgimento de uma "nuvem" coloidal que cresce à medida que a amostra se dissolve.

\section{Infiltração da Água}

A metodologia utilizada para avaliar e estimar a taxa de infiltração da água em um solo foi a do método de infiltrômetro de cilindros concêntricos. $O$ ensaio foi realizado do mesmo jeito que com os dois conjuntos de anéis concêntricos, sendo um de PVC com 25 e $50 \mathrm{~cm}$ de diâmetro e outro de metal com 16 e $25 \mathrm{~cm}$ de diâmetro, ambos com $30 \mathrm{~cm}$ de altura. Os anéis foram enterrados (aproximadamente $10 \mathrm{~cm}$ ) com o auxílio de uma régua e de uma marreta. Em seguida foi adicionada água em ambos os anéis, e foram realizadas as medições da lâmina d'água com intervalos de tempo pré-determinados (zero (0), cinco (5), quinze (15), trinta (30) minutos. Foi repetida a leitura de trinta em trinta minutos até a taxa de infiltração se tornasse constante para valor do volume infiltrado.

\section{RESULTADOS}

\section{Propriedades Físicas do Solo}

A Figura 2, apresenta a curva granulométrica do solo, obtida a partir do peneiramento e sedimentação. A distribuição das frações granulométricas determinadas a partir da referida curva são apresentadas na Tabela 2.

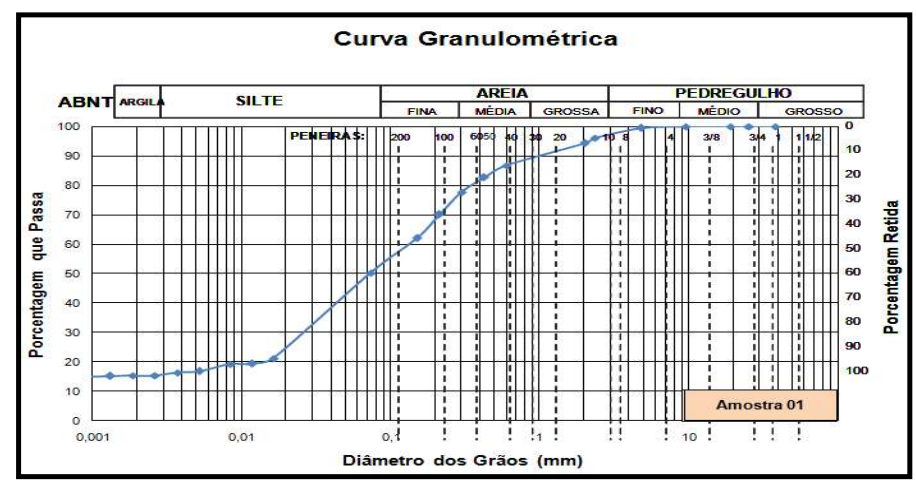

Figura 2: Curva granulométrica

Conforme a análise granulométrica, o solo é areno siltoso com pequena quantidade de pedregulho, e $55 \%$ de finos.

Tabela 2: Composição granulométrica do solo.

\begin{tabular}{|c|c|c|c|c|c|}
\hline \multicolumn{6}{|c|}{ Composição Granulométrica ( \% ) } \\
\hline \multirow{2}{*}{ Argila } & \multirow{2}{*}{ Silte } & Areia & & & \multirow{2}{*}{ Pedregulho } \\
\hline & & Fina & Média & Grossa & \\
\hline 16,0 & 39,0 & 28,0 & 13,0 & 2,0 & 2,0 \\
\hline
\end{tabular}


Considerando de classificação o Soil Conservation Service o solo analisado se enquadra como solos arenosos com baixo teor de argila total igual, sofrendo oscilações dependendo da textura e quantidade de matéria orgânica presente no solo, pertencendo ao grupo B. A Tabela 3 mostra os resultados dos ensaios de caracterização dos aspectos físicos do solo.

Tabela 3: Resultados da caracterização física do solo.

\begin{tabular}{ll}
\hline Análises Físicas do Solo & \\
\hline Ensaios & Resultados \\
\hline Massa especifica do grão & $2,65 \mathrm{~g} / \mathrm{cm}^{3}$ \\
\hline Massa especifica aparente seco & $1,482 \mathrm{~g} / \mathrm{cm}^{3}$ \\
\hline Limite de Liquidez & $32,00 \%$ \\
\hline Limite de Plasticidade & $14,82 \%$ \\
\hline Índice de Plasticidade & $17,20 \%$ \\
\hline Porosidade & $37,80 \%$ \\
\hline
\end{tabular}

A partir do valor encontrado da massa especifica do grão, pode-se determinar que foi devido à presença do mineral quartzo e caulinita, conforme a Tabela4.

Tabela 4: Massa específica dos grãos de argilominerais e matéria orgânica em solos.

\begin{tabular}{ll}
\hline Mineral & Massa específica $\left(\mathbf{g} / \mathbf{c m}^{\mathbf{3}}\right)$ \\
\hline Goethita & 3,3 \\
\hline Quartzo & 2,65 \\
\hline Caulinita & 2,6 \\
\hline Gibsita & 2,34 \\
\hline Matéria Orgânica * & $1,0-2,0$ \\
\hline
\end{tabular}

O valor do limite de liquidez foi de $32 \%$ de umidade, sendo que, a partir desse percentual, o solo passa do estado sólido para o líquido. O limite de plasticidade obtido foi de 14,82 \% de umidade percentual em que o solo passa para o estado plástico.

A partir da diferença entre os limites se determina o índice de plasticidade, que foi de 17,2 \% valor que estabelece quando o solo passa do estrado plástico para o líquido, com base no valor encontrado permitiu estabelecer a plasticidade do solo, sendo a mesma classificado como altamente plástica, conforme representado na Tabela 5 .

Tabela 5: Classificação das argilas.

\begin{tabular}{ccc}
\hline Plasticidade & IP & Amostra \\
\hline Fracamente plástica & $1<\mathrm{IP}<7$ & - \\
\hline Medianamente plástica & $7<\mathrm{IP}<15$ & - \\
\hline Altamente plástica & $\mathrm{IP}>15$ & 17,2
\end{tabular}

Conforme a Carta de Plasticidade de Casagrande (Figura 3), empregada na classificação de SUCS, a amostra de solo pode ser classificada como sendo do grupo $\mathrm{CL}$, que são solos argilosos de baixa compressibilidade, esse grupo está situado a esquerda da linha B e entre a linha $U$ e a linha $A$.

A Tabela 6, apresenta a classificação de alguns solos típicos brasileiros que são determinados a partir dos valores encontrados no limite de liquidez e no índice de plasticidade do solo. 


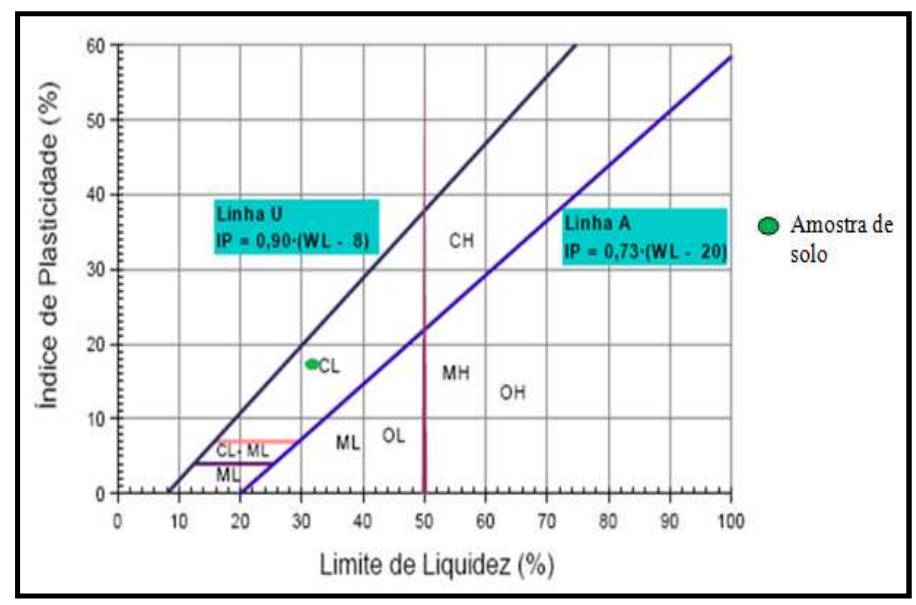

Figura 3: Gráfico da Carta de Plasticidade de Casagrande.

Tabela 6: Valores de LL e IP para alguns solos típicos brasileiros.

\begin{tabular}{lll}
\hline Solos & LL & IP \\
\hline Residuais de arenito (arenosos finos) & $29-44$ & $11-20$ \\
\hline Residual de gnaisse & $45-55$ & $20-25$ \\
\hline Residual de basalto & $45-70$ & $20-30$ \\
\hline Residual de granito & $45-55$ & $14-18$ \\
\hline Argilas orgânicas de várzeas quaternárias & 70 & 30 \\
\hline Argilas orgânicas de baixada litorânea & 120 & 80 \\
\hline Argila porosa vermelha de São Paulo & 65 a 85 & 25 a 40 \\
\hline Argila variegadas de São Paulo & 40 a 80 & 15 a 45 \\
\hline Areias argilosas variegadas de São Paulo & 20 a 40 & 5 a 15 \\
\hline Argilas duras, cinzas, de São Paulo & 64 & 42 \\
\hline
\end{tabular}

Assim de acordo com os valores encontrados na amostra pode-se dizer que a amostra de solo estudado é classificada como sendo um solo residual de arenito. Os ensaios de dispersão rápida com submersão em solução de $0.001 \mathrm{~N}$ de hidróxido de sódio mostraram que nos primeiros minutos a amostra de solo começou a se colapsar nos vértices, logo quando entrou em contato com a solução, no decorrer do tempo foi se destorroando aos poucos sempre preservando a forma da fase superior e sempre permanecendo a solução sem turbidez. Conforme a classificação proposta por SHERARD et. al. (1972), o solo é classificado como sendo não dispersivo, onde o torrão pode espalhar-se no fundo do recipiente, porém não se observa sinal de turvação causada por colóides em suspensão.

O ensaio de desagregação do solo foi realizado observando as alterações em um cubo de solo em três estágios de submersão. Os resultados da análise visual do primeiro estágio, ocorrida nos primeiros 15 minutos, verificou uma leve absorção da água, sem princípios de deformação da amostra que teve o contato da água na base da amostra. Na segunda observaram-se leves destorroamentos nos vértices no terço submerso nos primeiros minutos estabilizando após 5 minutos de ensaio. Na terceira fase foi observado o destorroamento da base para o topo do solo nos vértices da amostra quando submergida 2/3 de amostra. Na última fase ocorreu a submersão completa da amostra e já nos primeiros minutos houve o destorroamento dos vértices restantes deixando a amostra com a face superior apenas com a parte central ainda inderformada, e após 24 horas observou-se total destorroamento da amostra. A reação da amostra à inundação foi a de fraturamento, onde a amostra se quebra em fragmentos mantendo a forma original de parte das faces externas. A partir dos resultados obtidos nos ensaios de dispersão e desagregação, concluise a ausência de dispersão e colapso lento. É possível indicar a implantação da trincheira drenante, pois 
apesar da presença da colapsividade, o preenchimento da trincheira drenante reduziria o efeito deste comportamento. A Figura 4 e a Figura 5 mostram os resultados dos ensaios de infiltração com anéis concêntricos realizados na área de estudo.

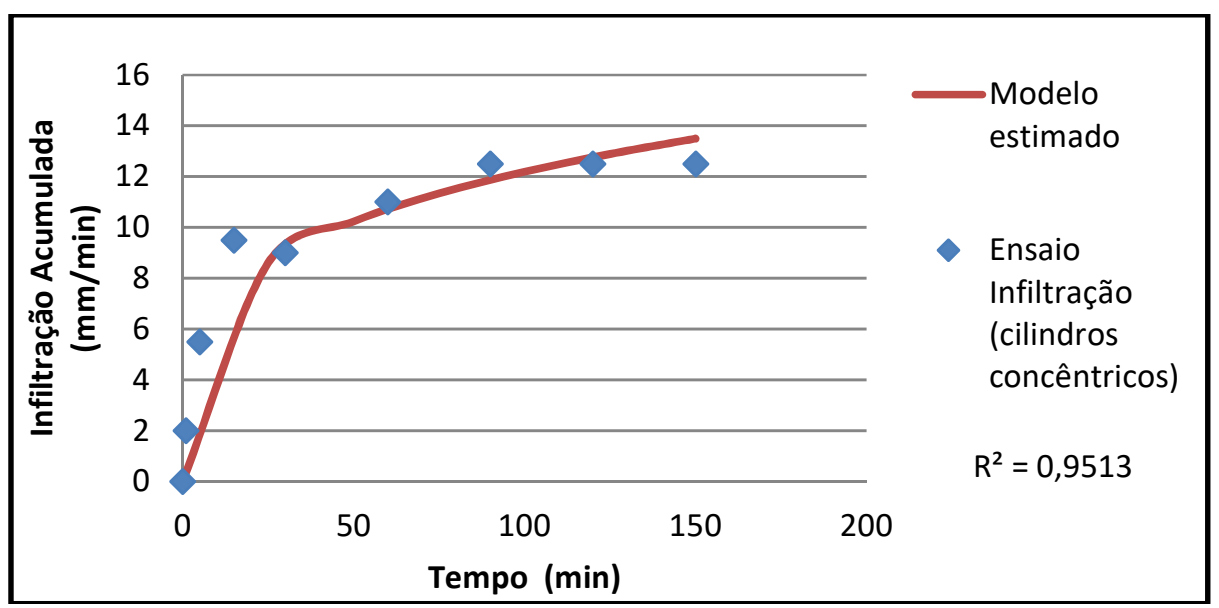

Figura 4: Ensaio infiltrômetro de PVC

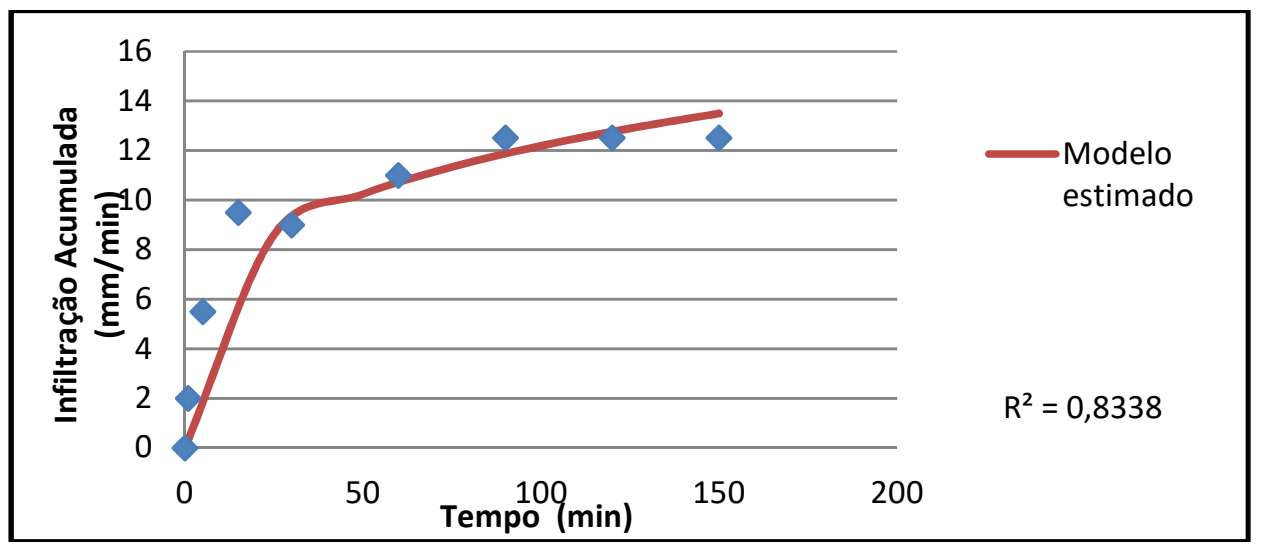

Figura 5: Ensaio infiltrômetro metálico.

Os resultados foram encontrados pelo método de ajuste numérico (mínimos quadrados) para ajustar os valores ao modelo de infiltração potencial de Kostiakov. Conforme o erro estimado, o resultado pelos anéis de PVC tem uma maior confiabilidade do que os anéis metálicos, assim obtendo os seguintes valores de infiltração acumulada e de velocidade de infiltração instantânea para os anéis de PVC e de Metal, que corresponde a 13, $5 \mathrm{~mm}$ e $19,86 \mathrm{~mm}$, e de $1,35882 \mathrm{~mm} / \mathrm{h}$ e $2,74968 \mathrm{~mm} / \mathrm{h}$. Os valores de condutividade hidráulica vertical encontrados para os anéis de PVC e de metal, foram 47,544 mm/h e 49,284 mm/h, conforme Tabela 7, sendo que o solo pertence ao grupo A correlacionável a franco arenoso. 0 valor obtido está acima dos $8 \mathrm{~mm} / \mathrm{h}$ proposto por Urbonas et al. (1993), para o solo da trincheira drenante. Tal fato não impede a aplicação da trincheira, mas indica a necessidade de maior filtração por parte do sistema.

Tabela 07: Grupos hidrológicos de solo e condutividade hidráulica saturada média para as classes texturais do USDA.

\begin{tabular}{lll}
\hline Grupo Hidrológico de Solo & Classe Textural & $\mathrm{Kv}(\mathrm{mm} / \mathrm{h})$ \\
$\mathrm{A}$ & Areia & 210 \\
& Areia Franca & 61,1 \\
& Franco Arenoso & 25,9 \\
\hline & Franco & 13,2 \\
$\mathrm{~B}$ & Franco Siltoso & 6,8 \\
\hline C & Franco Argiloso Arenoso & 4,3 \\
\hline
\end{tabular}




$\begin{array}{ll}\text { Franco Argiloso } & 2,3 \\ \text { Franco Argiloso Siltos } & 1,5 \\ \text { Argila Arenosa } & 1,2 \\ \text { Argila Siltosa } & 0,9 \\ \text { Argila } & 0,6\end{array}$

\section{CONCLUSÃO}

As análises das características geotécnicas do solo em estudo mostram que o solo é classificado como latossolos vermelho amarelo distrófico. As características do solo quanto a granulometria e plasticidade permite classifica-lo como $\mathrm{CL}$, tratando-se de solos com argilas com baixa compressibilidade com porosidade $37,8 \%$ compatível com materiais de natureza arenosa.

O ensaio de dispersão indica um caráter não dispersivo enquanto que o de desagregação indica um índice de colapsibilidade baixo. A ausência de dispersão não oferece risco ao funcionamento da trincheira, mas o comportamento de colapsividade indica a necessidade de escavação e preenchimento rápido da trincheira para que o mesmo não afete o comportamento da trincheira.

Foi obtido valores de condutividade hidráulica vertical a partir do ensaio de anéis concêntricos da ordem $49 \mathrm{~mm} / \mathrm{h}$. O projeto deve considerar a capacidade de drenagem do solo e quanto maior este parâmetro menor é o potencial de remoção de cargas do escoamento superficial e maior é o risco de contaminação do aquífero. Para compensar este valor de infiltração deve-se considerar no sistema uma camada com capacidade retenção de poluentes ou um dispositivo com esta finalidade a montante do mesmo.

\section{REFERÊNCIAS}

AZZOUT, Y.; BARRAUD, S.; CRES, F. N.; ALFAKIH, E.. Techniques alternatives en assainissement pluvial: choix, conception, realization etentretien. Paris: Lavoisier, 1994.

BAPTISTA, M. B.; NASCIMENTO, N. O.; BARRAUD, S. Técnicas compensatórias em drenagem urbana. Porto Alegre: ABRH (Associação Brasileira de Recursos Hídricos), 2005.

BARRAUD, S.; GAUTIER, A.; BARDIN, J. P.; RIOU, V., The impact of intentional infiltration on soil and groundwater- $a$ case study. In: INTERNATIONAL CONFERENCE ON INNOVATIVE TECHNOLOGIES IN URBAN DRAINAGE, 3. Anais. Lyon: Novatech 1988.

BRITO, D.. Metodologia para seleção de alternativas de sistemas de drenagem. Dissertação (Mestrado em Tecnologia Ambiental e Recursos Hídricos) - Universidade de Brasília, Brasília, 2006.

CARVALHO, E. L.. Avaliação geotécnica de poço de infiltração de águas pluviais. Tese (Doutorado em Geotécnia) - Universidade de Brasília, Brasília, 2013.
PINTO, C. S.. Curso básico de mecânica dos solos. São Paulo: Oficina de Textos, 2000.

SANTOS, L. F.. Cartografia geotécnica regional do município de Palmas/TO: área a oeste do meridiano 48 W. Gr. Dissertação (Mestrado em Geotecnia) - Universidade de Brasília, Brasília, 2000.

SILVA, J. P.. Estudos preliminares para implantação de trincheiras de infiltração. Dissertação (Mestrado em Geotecnia) - Universidade de Brasília, Brasília, 2007.

SOUZA, V. C. B.. Estudo experimental de trincheiras de infiltração no controle da geração do escoamento superficial. Tese (Doutorado em Engenharia de Recursos Hídricos e Saneamento Ambiental) - Instituto de Pesquisas Hidráulicas, Universidade Federal do Rio Grande do Sul, Porto Alegre, 2002.

TUCCI, C. E. M.. Impactos da variabilidade climática e o Uso do solo sobre os recursos hídricos. In: FÓRUM BRASILEIRO DE MUDANÇAS CLIMÁTICAS. Anais. Brasília, 2002.

URBONAS, B.; STAHRE, P.. Stormwater: best management, practices and detention for water quality drainage, and CSO management. Englewood Cliffs: Prentice Hall, 1993.

A CBPC - Companhia Brasileira de Produção Científica (CNPJ: 11.221.422/0001-03) detém os direitos materiais desta publicação. Os direitos referem-se à publicação do trabalho em qualquer parte do mundo, incluindo os direitos às renovaç̃̃es, expansões e disseminações da contribuição, bem como outros direitos subsidiários. Todos os trabalhos publicados eletronicamente poderão posteriormente ser publicados em coletâneas impressas sob coordenação da Sustenere Publishing, da Companhia Brasileira de Produção Científica e seus parceiros autorizados. Os (as) autores (as) preservam os direitos autorais, mas não têm permissão para a publicação da contribuição em outro meio, impresso ou digital, em português ou em tradução. 